\title{
Explant of a ball and cage valve 42 years after initial implant
}

\author{
Frank Battaglia, MD Candidate, ${ }^{a}$ Lisa Mielniczuk, BSc, MSc, MD, FRCPC, ${ }^{b}$ \\ Jean-Yves Dupuis, MD, FRCPC, ${ }^{c}$ and Vincent Chan, MD, MPH, FRCSC, ${ }^{\text {a,d }}$ Ottawa, Ontario, Canada
}

\footnotetext{
From the ${ }^{\mathrm{a} D i v i s i o n}$ of Cardiac Surgery, ${ }^{\mathrm{b}}$ Division of Cardiology, Department of Medicine, and ${ }^{\mathrm{c}}$ Division of Cardiac Anesthesiology, Department of Anesthesiology, University of Ottawa Heart Institute, Ottawa, Ontario, Canada; and ${ }^{\mathrm{d}}$ School of Epidemiology and Public Health, University of Ottawa, Ottawa, Ontario, Canada.

Disclosures: Authors have nothing to disclose with regard to commercial support.

Received for publication Aug 28, 2017; revisions received Nov 16, 2017; accepted for publication Nov 16, 2017; available ahead of print Jan 10, 2018.

Address for reprints: Vincent Chan, MD, MPH, FRCSC, University of Ottawa, H3405-40 Ruskin St, Ottawa, Ontario K1Y 4W7, Canada (E-mail: vchan@ottawaheart.ca).

J Thorac Cardiovasc Surg 2018;155:e147-8

$0022-5223 / \$ 36.00$

Copyright (C) 2017 by The American Association for Thoracic Surgery

https://doi.org/10.1016/j.jtcvs.2017.11.082
}

Our patient initially underwent mitral valve replacement with a Starr-Edwards (Edwards Lifesciences, Irvine, Calif) valve in 1974 for rheumatic mitral stenosis at Toronto General Hospital. She was anticoagulated with Coumadin for a target international normalized ratio of 2.5 to 3.5. From 1974 onward, the patient never experienced any significant thrombotic or hemorrhagic complications. However, in 2015, the patient developed increasing dyspnea and fatigue. Transthoracic echocardiography showed mildly elevated transprosthesis gradients, with early-onset pulmonary hypertension, tricuspid regurgitation, and right heart dysfunction (Figures 1 and 2).

Mitral valve re-replacement was recommended. In June of 2016, 42 years after initial implantation, the patient underwent surgery, during which extensive pannus formation was observed extending into the mitral orifice from the valve's sewing ring. The patient also had extensive mitral annular calcification. This annular calcification, along with the pannus, was debrided, and the Starr-Edwards valve was removed. The annulus was reconstructed, and the valve was re-replaced with a 25-mm On-X valve (CryoLife, Kennesaw, Ga). A biatrial cryomaze and concomitant tricuspid repair with a 27-mm Duran band was also performed. The postoperative echocardiogram showed no evidence of perivalvular leak and a mean transprosthesis gradient of $2 \mathrm{~mm}$ $\mathrm{Hg}$. The patient had an uneventful postoperative course and was discharged on postoperative day 9 without event. One year after surgery, the patient remained asymptomatic without functional limitations or evidence of hemorrhagic or thromboembolic events.

\section{DISCUSSION}

In 1960, the first ball-valve prostheses, named the "StarrEdwards" valve after its inventors, were used in 8 patients with class III-IV heart failure. Of these patients, 4 had mitral regurgitation, 1 had stenosis, and 3 had a combination of regurgitation and stenosis. That study represented one of humans. ${ }^{1}$

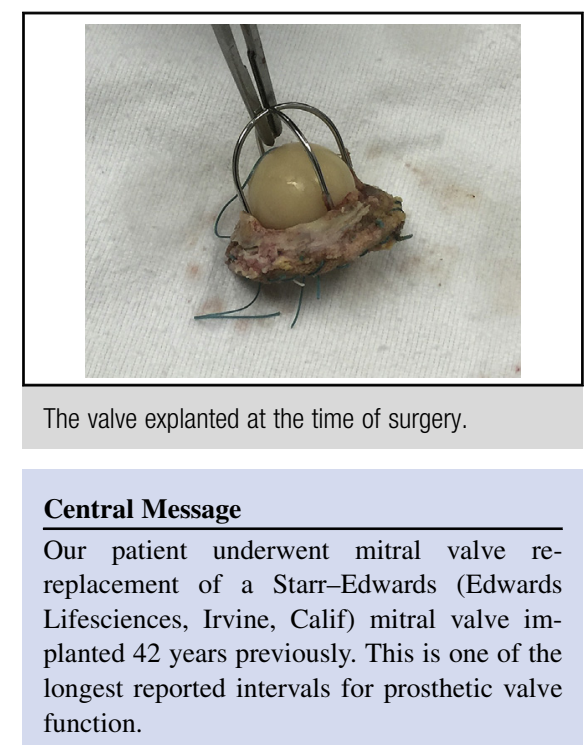

See Editorial Commentary page e 149.

the first successful trials of mitral valve prostheses in

The ball and cage design was initially chosen because it had no hinge, minimizing hemolysis and thrombus formation. The ball rotates randomly, which evenly distributes wear on the ball, and the lubricity of blood satisfactorily cushions and protects the components of the valve. ${ }^{2}$ The cage was made of stellite, the ball was made of silastic, and the sewing ring was made of Dacron. ${ }^{2}$ The device remained nearly unchanged for more than 40 years. $^{2}$

Although use of the Starr-Edwards valve improved heart failure symptoms for selected patients, thromboembolic events were the most common and severe complications of these valves. Early studies comparing the Starr-Edwards with biological valves showed patients receiving the StarrEdwards valve had an increased risk of thrombotic events compared with a tissue valve $(0.25 \%$ per patient-year vs $0.1 \%$ per patient-year). ${ }^{3}$ Therefore, recent advances in managing patients with mechanical heart valves include fastidious anticoagulation control. ${ }^{4}$ Notably, this patient was diligent in managing her international normalized ratio and avoided hemorrhagic and thromboembolic complications.

Despite advances in anticoagulation control, thromboembolism remained a major concern with the Starr-Edwards valve. Fifteen years after implantation, $50 \%$ of patients experienced a major thromboembolic event, of which $80 \%$ involved the cerebral circulation. ${ }^{5}$ In addition, patients often 


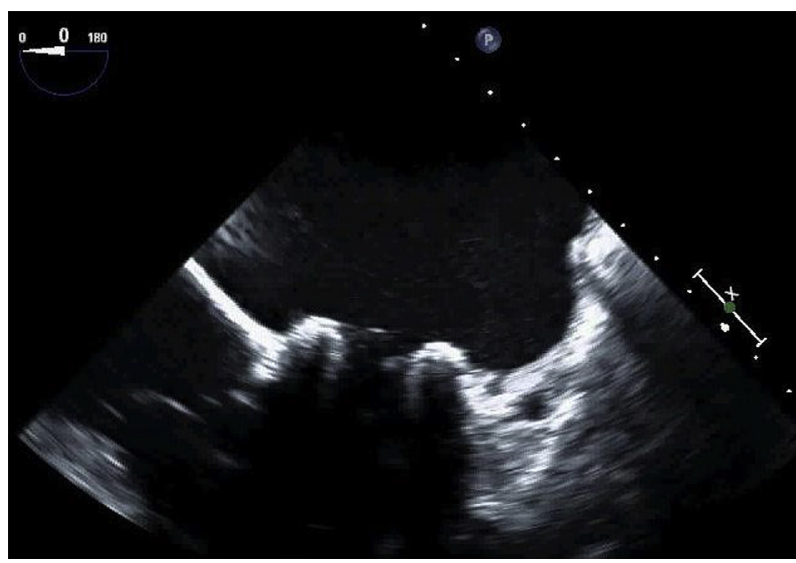

FIGURE 1. Starr-Edwards (Edwards Lifesciences, Irvine, Calif) valve in mitral position during systole. The Starr-Edwards mitral valve via transesophageal echocardiography in systole.

had hemolytic anemia. ${ }^{3}$ The Starr-Edwards valve was discontinued in 2007 after approximately 50 years of clinical use. ${ }^{5}$

The succeeding generation of mechanical heart valves included the tilting disc, followed by contemporary bileaflet valves. ${ }^{3}$ Institutionally, our preference has been to use the On-X valve. In a recent study evaluating mitral valve replacement with the On-X valve, reported rates of hemorrhage, major thromboembolism, valve-related reoperation, and valve-related mortality were $1.20 \%, 0.72 \%, 0.24 \%$, and $0.12 \%$, respectively. ${ }^{4}$ Notwithstanding, contemporary bileaflet valves, including the St Jude Medical valve (St Paul, Minn), have shown comparable hemodynamics yielding a favorable effective orifice area. ${ }^{6}$

Nevertheless, the Starr-Edwards has been shown to be extremely durable. ${ }^{5}$ The 10 -year freedom from valve failure (eg, infection, embolism, thrombosis, hemorrhage, perivalvular leak) was approximately $75 \%$, notably superior to its contemporaries. ${ }^{3}$ A 1984 study by McGoon and colleagues $^{5}$ found that although 16 of 147 patients with a

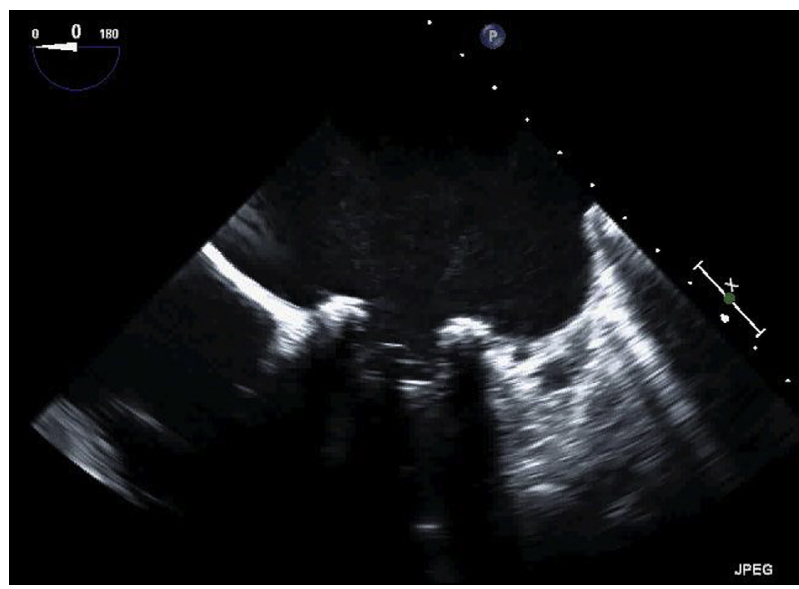

FIGURE 2. Starr-Edwards valve in mitral position during diastole. The Starr-Edwards mitral valve via transesophageal echocardiography in diastole.
Starr-Edwards valve in the mitral position experienced a paravalvular leak or dehiscence, only 3 patients experienced complications that may be due to primary malfunction of the valve apparatus, and only 1 of these complications (valve thrombosis) was fatal. ${ }^{5}$

In this case, one important decision was related to the timing of reoperative mitral surgery. This patient developed pulmonary hypertension with right heart failure with her existing mitral prosthesis. Although the regression of pulmonary hypertension remains unclear after mitral valve surgery, its presence is associated with worse late outcomes in patients after mitral surgery. ${ }^{7}$

Although the patient selected a mechanical prosthesis, a bioprosthetic valve may have been considered. The mitral annulus in this patient was calcified, and successful replacement included patch reconstruction of the atrial-ventricular groove. This may complicate second-time reoperative surgery if she were to develop bioprosthetic valve deterioration. Notwithstanding, valve-in-valve mitral valve replacement is emerging, although the efficacy and durability of this approach remain undetermined. ${ }^{8}$ As such, current guidelines related to patient age and heart valve prosthesis selection were adhered to.

\section{CONCLUSIONS}

We report the case of a patient who underwent mitral valve re-replacement with a contemporary mechanical prosthesis 42 years after initial mitral replacement with a Starr-Edwards valve. To our knowledge, this represents the longest interval for reoperation after Starr-Edwards mitral valve replacement for a patient in Canada and among the longest in the literature.

\section{References}

1. Starr A, Edwards ML. Mitral replacement: clinical experience with a ball-valve prosthesis. Ann Surg. 1961;154:726-40.

2. Starr A, Grunkemeier GL. Durability of the Starr-Edwards heart valve: early decisions led to successful results. Tex Heart Inst J. 2016;43:2-3.

3. Cobanoglu A, Grunkemeier GL, Aru GM, McKinley CL, Starr A. Mitral replacement: clinical experience with a ball-valve prosthesis. Twenty-five years later. Ann Surg. 1985;202:376-83.

4. Chan V, Jamieson WR, Lam BK, Ruel M, Ling H, Fradet G, et al. Influence of the On-X mechanical prosthesis on intermediate-term major thromboembolism and hemorrhage: a prospective multicenter study. J Thorac Cardiovasc Surg. 2010; 140:1053-8.e2.

5. McGoon MD, Fuster V, McGoon DC, Pumphrey CW, Pluth JR, Elveback LR. Aortic and mitral valve incompetence: long-term follow-up (10 to 19 years) of patients treated with the Starr-Edwards prosthesis. J Am Coll Cardiol. 1984;3: 930-8

6. Mostafa EA, El Midany AA, Taha AS, El Aasy SR, Doghish AA, Helmy A, et al. On-X versus St Jude Medical mechanical prosthesis, in mitral position: are we moving forward in design technology? J Cardiovasc Surg (Torino). July 28, 2017 [Epub ahead of print].

7. Coutinho GF, Garcia AL, Correia PM, Branco C, Antunes MJ. Negative impact of atrial fibrillation and pulmonary hypertension after mitral valve surgery in asymptomatic patients with severe mitral regurgitation: a 20-year follow-up. Eur J Cardiothorac Surg. 2015;48:548-56.

8. Yoon SH, Whisenant BK, Bleiziffer S, Delgado V, Schofer N, Eschenbach L, et al. Transcatheter mitral valve replacement for degenerated bioprosthetic valves and failed annuloplasty rings. J Am Coll Cardiol. 2017; 70:1121-31. 